\title{
Environmental connections of novel avian-origin H7N9 influenza virus infection and virus adaptation to the human
}

\author{
LI Jun $^{1 \dagger}$, YU XinFen ${ }^{1 \dagger}$, PU XiaoYing ${ }^{1 \dagger},{\text { XIE } \mathrm{Li}^{1 \dagger}, \text { SUN YongXiang }}^{2 \dagger}$, XIAO HaiXia $^{5}$, \\ WANG FenJuan ${ }^{2}$, DIN Hua ${ }^{1}$, WU Ying ${ }^{3}$, LIU Di ${ }^{3,6}$, ZHAO GuoQiu ${ }^{1}$, LIU Jun ${ }^{3,4^{*}}$ \\ \& PAN JingCao ${ }^{1 *}$ \\ ${ }^{1}$ Hangzhou Center for Disease Control and Prevention, Hangzhou 310021, China; \\ ${ }^{2}$ Xiaoshan Center for Disease Control and Prevention, Hangzhou 311201, China; \\ ${ }^{3}$ CAS Key Laboratory of Pathogenic Microbiology and Immunology, Institute of Microbiology, Chinese Academy of Sciences, Beijing 100101, \\ China; \\ ${ }^{4}$ National Institute for Viral Disease Control and Prevention, Chinese Center for Disease Control and Prevention, Beijing 102206, China; \\ ${ }^{5}$ Laboratory of Protein Engineering and Vaccine, Tianjin Institute of Industrial Biotechnology, Chinese Academy of Sciences, Tianjin 300308, \\ China; \\ ${ }^{6}$ Network Information Center, Institute of Microbiology, Chinese Academy of Sciences, Beijing 100101, China
}

Received May 1, 2013; accepted May 6, 2013; published online May 7, 2013

\begin{abstract}
A novel H7N9 influenza A virus has been discovered as the causative identity of the emerging acute respiratory infection cases in Shanghai, China. This virus has also been identified in cases of infection in the neighboring area Hangzhou City in Zhejiang Province. In this study, epidemiologic, clinical, and virological data from three patients in Hangzhou who were confirmed to be infected by the novel H7N9 influenza A virus were collected and analyzed. Human respiratory specimens and chicken feces from a contacted free market were tested for influenza virus by real-time reverse transcription PCR (RT-PCR) and sequencing. The clinical features of the three cases were similar featured with high fever and severe respiratory symptoms; however, only one of the patients died. A certain degree of diversity was observed among the three Hangzhou viruses sequenced from human samples compared with other reported H7N9 influenza A viruses. The sequences of the novel avian-origin H7N9 influenza viruses from Hangzhou City contained important amino acid substitutions related to human adaptation. One of the Hangzhou viruses had gained a novel amino acid substitution (Q226I) in the receptor binding region of hemagglutinin. More importantly, the virus sequenced from the chicken feces had a 627E substitution in the PB2 protein instead of the mammalian-adapted $627 \mathrm{~K}$ substitution that was found in the PB2 proteins from the Hangzhou viruses from the three patients. Therefore, the newly-emerging H7N9 virus might be under adaptation pressure that will help it "jump" from avian to human hosts. The significance of these substitutions needs further exploration, with both laboratory experiments and extensive field surveillance.
\end{abstract}

H7N9 influenza A virus, human adaptation, epidemiology, substitution

Citation: $\quad$ Li J, Yu X F, Pu X Y, et al. Environmental connections of novel avian-origin H7N9 influenza virus infection and virus adaptation to the human. Sci China Life Sci, 2013, 56: 485-492, doi: 10.1007/s11427-013-4491-3

A novel avian-origin reassortant influenza A (H7N9) virus associated with severe lower respiratory tract diseases has

$\dagger$ Contributed equally to this work

*Corresponding author (email: jingcaopan@gmail.com; liuj333@gmail.com) emerged in east China in February 2013 [1]. Starting from Anhui Province and Shanghai Municipality, the reported cases expanded to adjacent provinces, including Jiangsu, Zhejiang, and subsequently, to some farther provinces, such as Henan, and Beijing Municipality. To date, over 100 hu- 
man infection cases, including more than 20 deaths, have been reported in China.

Preliminary analyses have shown that the H7N9 viruses responsible for this outbreak are novel reassortants [2,3]. A substitution of Q226L (in the H3 numbering system) at the 210-loop in the hemagglutinin (HA) gene, which has been shown to change the binding of avian- to human-type receptor, was found in the two viruses from the Shanghai and Anhui patients; while, the virus from the first case in Shanghai had substitution 226Q. The Q226L substitution might increase the ability of the virus to be transmitted by air ( $\mathrm{Q}$ is the avian signature; $\mathrm{L}$ is the mammal signature) [4,5]. Moreover, the E627K substitution (avian vs. mammal signature) in the PB2 gene, which has been associated with improved virus replication and increased virulence in mice [6-8], was also observed in the newly identified virus in human, and this too may contribute to the human infection and severe disease.

Here, we report three cases of humans in Hangzhou City in Zhejiang Province infected with the novel avian-origin influenza A (H7N9) virus. Connections of the human infection to the virus detected in the environment were also determined. Furthermore, we identified an influenza A (H7N9) virus in one patient sample which had a new Q226I mammal-signature substitution. This substitution may play an important role in the host adaptation of the H7N9 virus. Interestingly, the virus from chicken feces had the $627 \mathrm{E}$ substitution in the PB2 protein instead of the mammalianadapted $627 \mathrm{~K}$ substitution that was in the PB2 proteins of the viruses from the patients. Therefore, it seems that the newly-emerging virus might be under the adaptation pressure for it to "jump" from avian to human hosts.

\section{Materials and methods}

\subsection{Epidemiological investigation}

At the end of March and in early April 2013, three patients from Hangzhou City in Zhejiang Province were hospitalized with symptoms of fever, coughing, and severe acute respiratory illness (SARI). Some respiratory pathogens such as seasonal influenza viruses (H1, H3), the 2009 pH1N1 influenza virus, and avian influenza viruses (H5N1, H9N2) were eliminated by real time RT-PCR assay. Subsequently, nasopharyngeal aspirate specimens from Patient 1 and throat-swab specimens from Patients 2 and 3 were sent to the Hangzhou Center for Disease Control and Prevention. Standardized procedures of epidemiology investigation were carried out. Retrospective information related to demographic characteristics, possible routes of acquisition of the virus, clinical symptoms, onset and progression of illness, and underlying medical treatment was collected.

\subsection{Specimen collection and identification of causative pathogen}

Human upper respiratory tract specimens from all three patients were collected in specimen tubes with viral-transport medium (Hank's buffer). The samples were test in the laboratory within $24 \mathrm{~h}$. Environmental specimens such as smear specimens from the surface of poultry cages, and poultry feces from the free market which Patient 2 may visit before the onset of the illness were also collected and tested. Real-time RT-PCR experiments were performed using the RNA which was extracted from the samples using the RNeasy Mini Kit (QIAGEN, Germany). The H7N9 infections of Patients 2 and 3 were confirmed by real-time RT-PCR assay using influenza subtype-specific primers provided by the Chinese Center for Disease Control and Prevention [1]. The H7N9 infection of Patient 1 was confirmed by comparing the HA, neuraminidase (NA) and PB2 sequences to the reference sequences [1].

\subsection{Viral genome sequencing}

The cDNA of eight complete gene segments were amplified using a PrimeScript II 1st Strand cDNA Synthesis Kit (TaKaRa, Japan) and Ex-taq HS (TaKaRa, Japan) according to the manufacturers' instructions. The amplified PCR products were then sequenced on an ABI 3730 automatic DNA analyzer (Life Technologies, USA) with ABI BigDye Terminator V3.1 cycle sequencing kit (Life Technologies, USA) at Sangon (Shanghai, China) immediately after the pathogen was confirmed to be the influenza A (H7N9) virus. The sequences of the viral gene segments of four viruses have been deposited in the GenBank with the following accession numbers: A/Hangzhou/1/2013: PB2 (KF001507), PB1 (KF001508), PA (KF001509), HA (KC853766), NP (KF001510), NA (KC853765), MP (KC853764), NS (KF001511); A/Hangzhou/2/2013: PB2 (KF001512), HA (KF001513), NA (KF001514); A/Hangzhou/3/2013: PB2 (KF001515), HA (KF001516), NA (KF001517); A/environment/Hangzhou/34/2013: PB2 (KF001518), HA (KF001519), NA (KF001520).

\subsection{Phylogenetic analysis}

The public sequences used in this study were downloaded from the Influenza Virus Resource database [9]. Phylogenetic trees for each of the gene segments were built using the maximum-likelihood methods under the General Time Reversible (GTR) model [10], to analyze the nucleotide substation with gamma-distributed rates among sites. All the phylogenetic trees were built with 1000 times bootstraps using the software RAxML [11]. 


\section{Results}

\subsection{Epidemiological and clinical features of the cases in Hangzhou City, Zhejiang Province}

Epidemiological and clinical information were collected from the patients' medical records, as well as from interviews with them and their relatives. Details of the investigation are recorded in Table S1. Patient 1 was a 38-year-old man with a history of hepatitis B virus infection and the positive hepatitis B surface antigen was detected. The man was a cook who had visited a poultry market every other day before the onset of his symptoms. He had high fever and cough at the onset of the illness. Patient 2 was a 67-year-old man who had a history of hypertension and nasitis. One week before the onset of the symptoms, he had visited a free market and bought two live quails which were butchered in the market. He cooked the quail himself and ate some of it. No other poultry contact in the two weeks before the onset of the illness was reported by Patient 2 . Patient 2 also had high fever, cough, and sputum production at the onset of the illness. Patient 3 was a 79-year-old man. He had no known history of exposure to live birds during the two weeks before the onset of symptoms. This patient had a cough and was found to have high fever on admission.

The general clinical features of the three Hangzhou patients with confirmed infections of the avian influenza A (H7N9) virus were similar to the three cases reported previously in Shanghai and in Anhui Province [1]. All three patients presented with high fever, cough, shortness of breath, and a history of sputum production. In Patient 1, the sputum was bloodstained, which was not reported in the three H7N9 virus infected cases in the previous study [1]. None of the patients had diarrhea, conjunctivitis, or rash. Physical examination of the chest in all three patients revealed respiratory distress and crackles, and rapid breathing in Patients 1 and 3. The white cell counts were normal for the three cases. The levels of creatine kinase and lactate dehydrogenase were increased in all three patients. Bilateral or unilateral ground-glass opacities and pleural effusion were observed by chest radiography (Figure 1).

Antibiotic therapy combined with glucocorticoids was administered to all three patients. Antiviral therapy and intravenous immunoglobulin were given to Patients 2 and 3. Patient 1 was admitted to the intensive care unit and intubated seven days after admission. Pneumonedema and acute respiratory distress syndrome developed in this patient and he died on day 21 after the onset of his illness. Patients 2 and 3 were transferred to negative pressure wards after the laboratorial confirmation of the H7N9 infection and their vital signs gradually improved.

\subsection{Causative pathogen of the infections and the envi- ronmental connection}

The RT-PCR and sequencing results for the amplified PCR products confirmed that H7N9 influenza virus was the causative agent of the illness and death for Patient 1. For Patients 2 and 3, the infection of influenza A (H7N9) virus was confirmed by real-time RT-PCR. The RT-PCR and sequence confirmed-viruses identified in Hangzhou from Patients 1, 2 and 3 were named A/Hangzhou/1/2013 (H7N9) (Hangzhou/1), A/Hangzhou/2/2013(H7N9) (Hangzhou/2) and A/Hangzhou/3/2013(H7N9) (Hangzhou/3), respectively. Environmental specimens related to Patient 2 were also tested. Poultry cage swabs and feces from the free market that Patient 2 visited one week before the onset of the symptoms were positive for the novel avian influenza A (H7N9) virus. We named this environmental virus A/environment/Hangzhou/34/2013(H7N9) (Env/Hangzhou).

\subsection{Sequence diversity of H7N9 Hangzhou viruses}

A phylogenic tree was constructed after aligning multiple H7 sequences from the Hangzhou viruses and from other


Figure 1 Chest radiographs. A, Computed tomography scan of the chest of Patient 1 was obtained on day 6 after the onset of the illness. Consolidation of inferior lobe of right lung and bilateral patches of higher density shadow can be seen. B, Chest radiographs of Patient 1 on day 11 . Bilateral ground-glass opacity and consolidation can be seen. 
human H7N9 viruses that were available online, together with other publicly available $\mathrm{H} 7$ influenza virus sequences. The tree built using the HA sequences revealed that all the H7N9 derived H7 sequences clustered in one branch. The HA sequence which was most similar to the H7N9 HA sequences was A/duck/Zhejiang/10/2011_H7N3. The Hangzhou/1, Hangzhou/2 and Hangzhou/3 sequences fell into different positions within the cluster (Figure 2). When this small cluster was examined in more detail, we found that the Env/Hangzhou and Hangzhou/2 sequences were the closest to each other, while the Hangzhou/1 and Hangzhou/3 sequences were located in different positions on the branch. This result clearly shows possible transmission relatedness between the Env/Hangzhou and infection of Patient 2 . The phylogenic clustering of the sequences of other proteins from the four new H7N9 viruses found in Hangzhou was quite similar to the phylogenic tree based on the HA sequences (data not shown). These data suggested that a variety of H7N9 viruses were circulating in Hangzhou. It is uncertain whether the diversity of H7N9 in Hangzhou was the result of host adaptation, or the diversity pre-existed before its transmission to human from avian species.

\subsection{Identification of a novel "human adaptation" sub- stitution Q226I in the hemagglutinin gene}

Sequence characteristics and the main residue features in the H7N9 viruses from Hangzhou were determined by aligning the HA amino acid sequences to HA sequences from other reported H7N9 human viruses (Table 1). The four Hangzhou HA sequences all contained the same marker $(\mathrm{P} 42 \mathrm{~S})$ for antiviral resistance at the M2 protein amantadine-binding site. On the other hand, the NA sequences of the four Hangzhou viruses all possessed drug sensitive characteristics, having the $120 \mathrm{E}, 276 \mathrm{H}$, and 294R (292R in the N2 numbering system) residues in their sequences. Other amino acid variations which are closely related with host preference, virus virulence, and drug resistance in other reported $\mathrm{H} 7 \mathrm{~N} 9$ human viruses were also observed in the HA, NA and PB2 sequences from the four Hangzhou viruses (Table 1).

Hangzhou/2, Hangzhou/3 and Env/Hangzhou have the same Q226L substitution (in the H3 numbering system) at the receptor binding site of HA as the Anhui/1 and Shanghai/2 viruses, while 226Q was observed in the HA of Shanghai/1 virus [1]. A laboratory-manipulated Q226L mutation in the 210-loop of H5 HA has been reported to contribute to the high-affinity binding of the viruses to the human receptor, which might increase the ability of the virus to be transmitted by air in mammals [4,5]. Interestingly, we found that the Hangzhou/1 virus had a novel Q226I substitution in the 210-loop of HA (Figure 3). This Q226I substitution in the sequence of the HA from Hangzhou/1 was observed for the first time in the H7 and H5 subtypes. Based on all the currently available HA sequences from H7N9 viruses, we found that there was a diverse distribution of $\mathrm{Q}$, L, and I residues at position 226 in these HAs (Figure 4).

\subsection{Substitution of $627 \mathrm{~K}$ in the $\mathrm{PB2}$ sequence in the human-infecting H7N9 virus and the $627 \mathrm{E}$ in the envi- ronmental H7N9 virus}

A virulence-associated substitution $\mathrm{E} 627 \mathrm{~K}$ was found in the PB2 proteins of the Hangzhou/1, Hangzhou/2 and Hangzhou/3 viruses (Figure 4); however, 627E was observed in the PB2 sequence of the Env/Hangzhou virus from the poultry feces which were collected from the free market that Patient 2 visited. This finding indicates that the adaptation pressure for species adaptation from avian to human may

Table 1 Molecular analysis of important amino acids in the PB2, HA, NA, M1, M2 and NS1 proteins associated with interspecies transmission and drug resistance of $\mathrm{H} 7 \mathrm{~N} 9$ viruses

\begin{tabular}{|c|c|c|c|c|c|c|c|c|c|c|c|}
\hline \multirow[b]{2}{*}{ Protein $^{a}$} & \multirow{2}{*}{\multicolumn{2}{|c|}{$\begin{array}{l}\text { Mutations responsible for } \\
\text { viral phenotype change }\end{array}$}} & \multicolumn{9}{|c|}{ H7N9 influenza viruses ${ }^{\text {b) }}$} \\
\hline & & & \multirow{2}{*}{$\frac{\text { Hangzhou/1 }}{\mathrm{K}}$} & \multirow{2}{*}{$\begin{array}{c}\text { Hangzhou/ } \\
2 \\
\mathrm{~K}\end{array}$} & \multirow{2}{*}{$\begin{array}{c}\text { Hangzhou/ } \\
3 \\
\mathrm{~K}\end{array}$} & \multirow{2}{*}{$\begin{array}{c}\begin{array}{c}\text { Env/ } \\
\text { Hangzhou }\end{array} \\
E\end{array}$} & \multirow{2}{*}{$\begin{array}{c}\text { Zhejiang/ } \\
\text { DTID-ZJU01 } \\
E\end{array}$} & \multirow{2}{*}{$\begin{array}{c}\text { Chicken/ } \\
\text { Zhejiang } \\
\text { E }\end{array}$} & \multirow{2}{*}{$\begin{array}{c}\text { Shanghai/ } \\
1 \\
\mathrm{~K}\end{array}$} & \multirow{2}{*}{$\begin{array}{c}\text { Shanghai/ } \\
2 \\
\mathrm{~K}\end{array}$} & \multirow{2}{*}{$\begin{array}{c}\text { Anhui/ } \\
1 \\
\mathrm{~K}\end{array}$} \\
\hline PB2 & Adaptation to mice & E627K & & & & & & & & & \\
\hline & & D701N & $\mathrm{D}$ & $\mathrm{D}$ & $\mathrm{D}$ & $\mathrm{D}$ & $\mathrm{N}$ & $\mathrm{D}$ & $\mathrm{D}$ & $\mathrm{D}$ & $\mathrm{D}$ \\
\hline \multirow[t]{3}{*}{ HA } & Cleavage site & & PEIPKGR*GLF & $f^{c)}$ & / & I & l & I & l & I & l \\
\hline & Receptor binding site ${ }^{\mathrm{d})}$ & Q226L & I & $\mathrm{L}$ & $\mathrm{L}$ & $\mathrm{L}$ & $\mathrm{L}$ & Q & Q & $\mathrm{L}$ & $\mathrm{L}$ \\
\hline & Stalk deletion & & $69-73$ & - & - & $69-73$ & $69-73$ & $69-73$ & $69-73$ & $69-73$ & $69-73$ \\
\hline NA & Antiviral resistance & R294K & $\mathrm{R}$ & $\mathrm{R}$ & $\mathrm{R}$ & $\mathrm{R}$ & $\mathrm{R}$ & $\mathrm{R}$ & $\mathrm{K}$ & $\mathrm{R}$ & $\mathrm{R}$ \\
\hline \multirow[t]{2}{*}{ M1 } & $\begin{array}{l}\text { Increase virulence in } \\
\text { mice }\end{array}$ & N30D & $\mathrm{D}$ & - & - & - & $\mathrm{D}$ & $\mathrm{D}$ & $\mathrm{D}$ & $\mathrm{D}$ & $\mathrm{D}$ \\
\hline & & $\mathrm{T} 215 \mathrm{~A}$ & A & - & - & - & A & A & A & A & A \\
\hline M2 & Antiviral resistance & S31N & $\mathrm{N}$ & - & - & - & $\mathrm{N}$ & $\mathrm{N}$ & $\mathrm{N}$ & $\mathrm{N}$ & $\mathrm{N}$ \\
\hline NS1 & $\begin{array}{c}\text { Increase virulence in } \\
\text { mice }\end{array}$ & $\mathrm{P} 42 \mathrm{~S}$ & $S$ & - & - & - & $S$ & S & S & S & $\mathrm{S}$ \\
\hline
\end{tabular}

a) Numbering of all the protein sequences, except the HA sequences, begins with the first ATG start codon (methionine). b) The full names of the viruses are listed in the legend of Figure 2. c) Forward slashes indicate that the cleavage site is similar to the cleavage site in the Hangzhou/1 protein. d) The positions are numbered based on the $\mathrm{H} 3$ numbering system. 


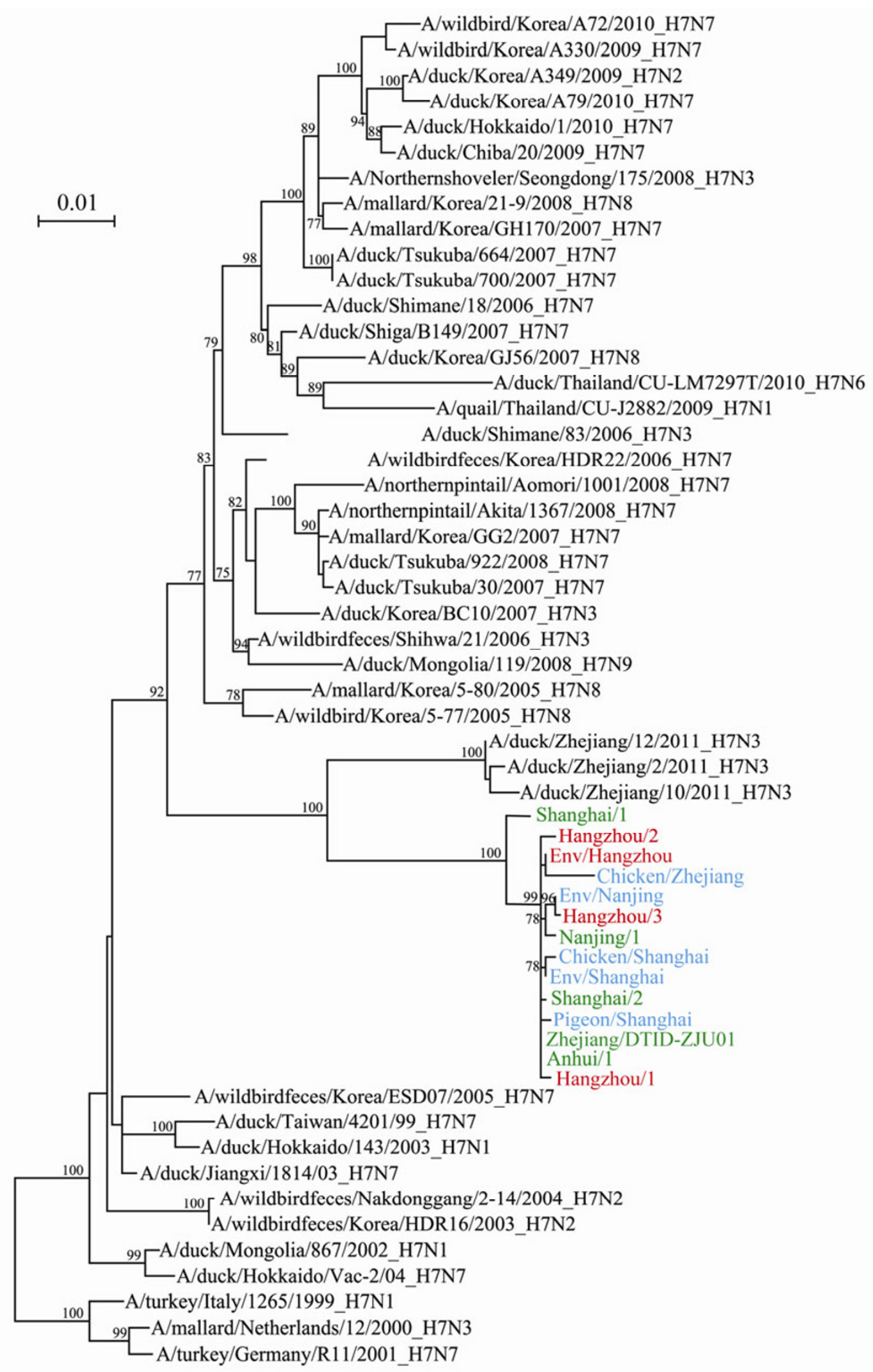

Figure 2 Phylogenetic tree based on HA sequences. The tree was generated using the maximum likelihood method with 1000 bootstrap replicates. The virus strains from this study are in red; the publicly available human H7N9 viruses are in green, and the other remaining H7N9 viruses are in cyan. Shanghai/1, A/Shanghai/1/2013; Chicken/Zhejiang, A/Chicken/Zhejiang/DTID-ZJU01/2013; Env/Nanjing, A/Environment/Nanjing/2913/2013; Nanjing/1, A/ Nanjing/1/2013; Chicken/Shanghai, A/Chicken/Shanghai/S1053/2013; Env/Shanghai, A/environment/Shanghai/S1088/2013; Shanghai/2, A/Shanghai/ 2/2013; Pigeon/Shanghai, A/Pigeon/Shanghai/S1069/2013; Zhejiang/DTID-ZJU01, A/Zhejiang/DTID-ZJU01/2013; Anhui/1, A/Anhui/1/2013. 


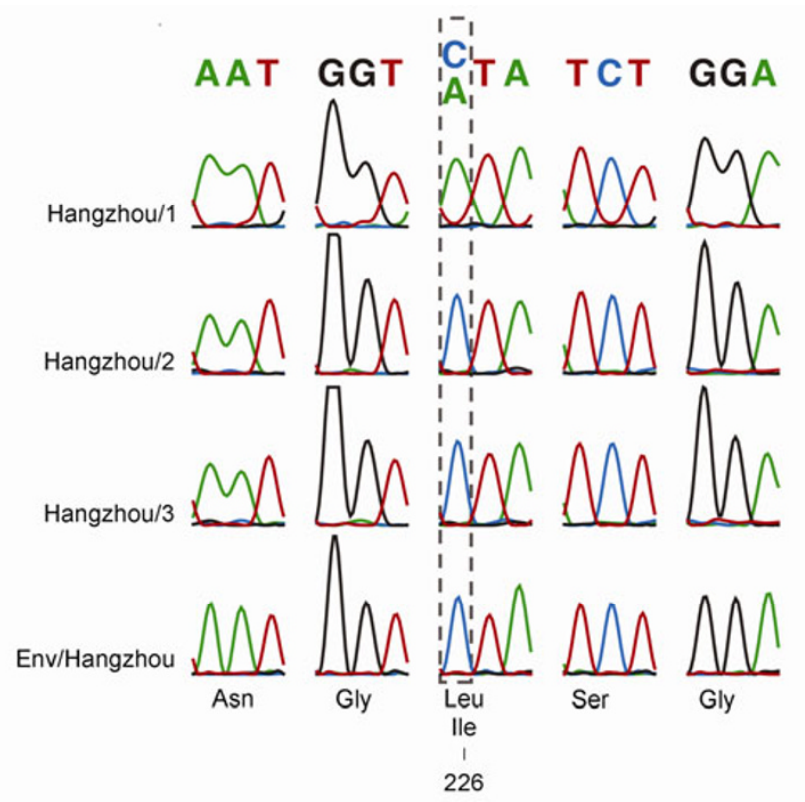

Figure 3 Chromatogram of the HA sequences flanking the amino acids at position 226 . The dashed boxes show the nonsynonymous substitutions. The $226 \mathrm{I}$ substitution in the HA of Hangzhou/1 is compared with the $226 \mathrm{~L}$ in the other three viruses.

exist in the newly-emerging H7N9 virus.

\section{Discussion}

We described three infected cases in Hangzhou City and identified the novel reassortant influenza A (H7N9) viruses in the respiratory specimens from these patients, as well as from environmental samples. Hangzhou City is close to Shanghai Municipality, where the first influenza A (H7N9) virus infections were reported [1]. Although later than the cases in Shanghai Municipality, the onset of the illness of two of the patients described here was reported around the same time as the illness of the patient in Anhui Province. Two of the three patients had a history of direct contact with live poultry or with local free markets. A closely related H7N9 virus was identified in the contacted environment of Patient 2. These data may provide direct evidence for the linking, or even transmission, of the avian H7N9 viruses to humans in these adjacent provinces of east China.

Although the clinical characteristics of the three cases reported here are very similar to the early cases reported previously in Anhui and Shanghai, namely high fever and severe respiratory symptoms, the genetic diversity of the genomes of the new Hangzhou H7N9 viruses was determined. The $\mathrm{H} 7$ phylogenetic trees placed the Hangzhou/1, Hangzhou/2 and Hangzhou/3 viruses on separate branches. Within the HA, NA and PB2 sequences from all the publicly available H7N9 viruses, we identified 36 sites with at least one amino acid mutation (Table 2). These data may indicate the independent and rapid evolution of the viruses in the natural reservoir and their independent introduction to human. However, based on the currently available H7N9 virus sequences, we found a series of other substitutions the majority of which were synonymous mutations (Table S2). The effects of these substitutions on the fitness of the virus-



Figure 4 Map of China showing the substitutions in the host-signatures from the different virus sequences. The provinces and municipal cities with reported H7N9 cases are in brown. The features of each of the sites are shown as follows: Province (number of human cases+number of environment/poultry cases), Gene (amino acid position): Residue (human); Residue (environment/poultry). Residues with avian-signatures are in purple; residues with mammalsignatures are in yellow. The $226 \mathrm{I}$ in the HA from A/Hangzhou/1/2013 is highlighted in red. 
Table 2 Variable amino acid residues in the HA, NA and PB2 proteins of H7N9 viruses ${ }^{\text {a) }}$

\begin{tabular}{|c|c|c|c|c|c|c|c|c|c|c|}
\hline Protein $^{\text {b) }}$ & Position & Hangzhou/1 & Hangzhou/2 & Hangzhou/3 & Env/Hangzhou & $\begin{array}{c}\text { Zhejiang/DTID- } \\
\text { ZJU01 }\end{array}$ & $\begin{array}{l}\text { Chicken/ } \\
\text { Zhejiang }\end{array}$ & Shanghai/1 & Shanghai/2 & Anhui/1 \\
\hline \multirow[t]{10}{*}{ PB2 } & 195 & $\mathrm{D}$ & $E$ & $\mathrm{D}$ & $\mathrm{D}$ & $\mathrm{D}$ & $\mathrm{D}$ & $\mathrm{D}$ & $\mathrm{D}$ & $\mathrm{D}$ \\
\hline & 197 & $\mathrm{~K}$ & $\mathrm{R}$ & $\mathrm{K}$ & $\mathrm{K}$ & $\mathrm{K}$ & $\mathrm{K}$ & $\mathrm{K}$ & $\mathrm{K}$ & $\mathrm{K}$ \\
\hline & 224 & $\mathrm{~S}$ & $\mathrm{~T}$ & $\mathrm{~T}$ & $\mathrm{~T}$ & $\mathrm{~T}$ & $\mathrm{~T}$ & $\mathrm{~T}$ & $\mathrm{~T}$ & $\mathrm{~T}$ \\
\hline & 292 & V & V & $\mathrm{V}$ & $\mathrm{V}$ & V & V & V & I & V \\
\hline & 395 & A & A & A & A & $\mathrm{S}$ & A & $\mathrm{S}$ & A & A \\
\hline & 461 & I & I & I & I & I & I & $\mathrm{V}$ & I & I \\
\hline & 559 & $\mathrm{~N}$ & $\mathrm{~T}$ & $\mathrm{~N}$ & $\mathrm{~N}$ & $\mathrm{~N}$ & $\mathrm{~N}$ & $\mathrm{~T}$ & $\mathrm{~N}$ & $\mathrm{~N}$ \\
\hline & $627^{c)}$ & $\mathrm{K}$ & $\mathrm{K}$ & $\mathrm{K}$ & $\mathrm{E}$ & $\mathrm{E}$ & $\mathrm{E}$ & $\mathrm{K}$ & $\mathrm{K}$ & $\mathrm{K}$ \\
\hline & $701^{\mathrm{c})}$ & $\mathrm{D}$ & $\mathrm{D}$ & $\mathrm{D}$ & $\mathrm{D}$ & $\mathrm{N}$ & $\mathrm{D}$ & $\mathrm{D}$ & $\mathrm{D}$ & D \\
\hline & 740 & D & D & A & D & D & D & D & D & D \\
\hline \multirow[t]{16}{*}{ HA } & 42 & $\mathrm{~V}$ & $\mathrm{~V}$ & $\mathrm{~V}$ & $\mathrm{~V}$ & V & $\mathrm{G}$ & $\mathrm{V}$ & $\mathrm{V}$ & V \\
\hline & 65 & $\mathrm{R}$ & $\mathrm{R}$ & M & $\mathrm{R}$ & $\mathrm{R}$ & $\mathrm{K}$ & $\mathrm{R}$ & $\mathrm{R}$ & $\mathrm{R}$ \\
\hline & 72 & $\mathrm{C}$ & $\mathrm{C}$ & $\mathrm{C}$ & $\mathrm{C}$ & $\mathrm{C}$ & $\mathrm{G}$ & $\mathrm{C}$ & $\mathrm{C}$ & $\mathrm{C}$ \\
\hline & 74 & $\mathrm{~L}$ & $\mathrm{~L}$ & $\mathrm{~L}$ & $\mathrm{~L}$ & $\mathrm{~L}$ & $\mathrm{P}$ & $\mathrm{L}$ & $\mathrm{L}$ & $\mathrm{L}$ \\
\hline & 75 & $\mathrm{~L}$ & $\mathrm{~L}$ & $\mathrm{~L}$ & $\mathrm{~L}$ & $\mathrm{~L}$ & $\mathrm{R}$ & $\mathrm{L}$ & $\mathrm{L}$ & $\mathrm{L}$ \\
\hline & 96 & I & I & I & I & I & M & I & I & I \\
\hline & 146 & A & A & A & A & A & A & $\mathrm{S}$ & A & A \\
\hline & 173 & M & I & M & M & M & M & M & M & M \\
\hline & 183 & $\mathrm{~S}$ & $\mathrm{~S}$ & $\mathrm{~S}$ & $S$ & $\mathrm{~S}$ & $\mathrm{~S}$ & $\mathrm{~N}$ & $\mathrm{~S}$ & $\mathrm{~S}$ \\
\hline & 195 & $\mathrm{~V}$ & V & $\mathrm{V}$ & $\mathrm{V}$ & V & V & $\mathrm{G}$ & $\mathrm{V}$ & V \\
\hline & 230 & $\mathrm{P}$ & $\mathrm{P}$ & $\mathrm{P}$ & $\mathrm{P}$ & $\mathrm{P}$ & $\mathrm{P}$ & $\mathrm{T}$ & $\mathrm{P}$ & $\mathrm{P}$ \\
\hline & $235^{\mathrm{d})}$ & I & $\mathrm{L}$ & $\mathrm{L}$ & $\mathrm{L}$ & $\mathrm{L}$ & Q & Q & $\mathrm{L}$ & $\mathrm{L}$ \\
\hline & 285 & $\mathrm{~N}$ & $\mathrm{~N}$ & $\mathrm{~N}$ & $\mathrm{~N}$ & $\mathrm{~N}$ & $\mathrm{~N}$ & D & $\mathrm{N}$ & $\mathrm{N}$ \\
\hline & 292 & $\mathrm{H}$ & $\mathrm{H}$ & $\mathrm{H}$ & $\mathrm{H}$ & $\mathrm{H}$ & $\mathrm{H}$ & $\mathrm{Y}$ & $\mathrm{H}$ & $\mathrm{H}$ \\
\hline & 410 & $\mathrm{~N}$ & $\mathrm{~N}$ & $\mathrm{~N}$ & $\mathrm{~N}$ & $\mathrm{~N}$ & $\mathrm{~N}$ & $\mathrm{~T}$ & $\mathrm{~N}$ & $\mathrm{~N}$ \\
\hline & 541 & V & V & $\mathrm{V}$ & $\mathrm{V}$ & V & $\mathrm{V}$ & A & $\mathrm{V}$ & V \\
\hline \multirow[t]{10}{*}{ NA } & 26 & I & - & I & I & I & I & I & M & I \\
\hline & 40 & $\mathrm{G}$ & - & $\mathrm{S}$ & $\mathrm{G}$ & $\mathrm{G}$ & $\mathrm{G}$ & $\mathrm{S}$ & $\mathrm{G}$ & $\mathrm{G}$ \\
\hline & $294^{\mathrm{e})}$ & $\mathrm{R}$ & $\mathrm{R}$ & $\mathrm{R}$ & $\mathrm{R}$ & $\mathrm{R}$ & $\mathrm{R}$ & $\mathrm{K}$ & $\mathrm{R}$ & $\mathrm{R}$ \\
\hline & 305 & I & I & $\mathrm{V}$ & I & I & I & I & I & I \\
\hline & 345 & $\mathrm{~N}$ & $\mathrm{~N}$ & I & $\mathrm{N}$ & $\mathrm{N}$ & $\mathrm{N}$ & $\mathrm{N}$ & $\mathrm{N}$ & $\mathrm{N}$ \\
\hline & 428 & $\mathrm{~L}$ & $\mathrm{~L}$ & $\mathrm{~L}$ & $\mathrm{~L}$ & $\mathrm{~L}$ & $\mathrm{~V}$ & $\mathrm{~L}$ & $\mathrm{~L}$ & $\mathrm{~L}$ \\
\hline & 439 & W & W & W & W & $\mathrm{L}$ & W & W & W & W \\
\hline & 441 & $\mathrm{~T}$ & $\mathrm{~T}$ & $\mathrm{~T}$ & $\mathrm{~T}$ & $\mathrm{~T}$ & A & $\mathrm{T}$ & $\mathrm{T}$ & $\mathrm{T}$ \\
\hline & 442 & $\mathrm{~S}$ & $\mathrm{~S}$ & $\mathrm{~S}$ & $S$ & $\mathrm{G}$ & $\mathrm{G}$ & $S$ & $\mathrm{~S}$ & $S$ \\
\hline & 443 & $\mathrm{~N}$ & $\mathrm{~N}$ & $\mathrm{~N}$ & $\mathrm{~N}$ & D & $\mathrm{N}$ & $\mathrm{N}$ & $\mathrm{N}$ & $\mathrm{N}$ \\
\hline
\end{tabular}

a) The full names of the viruses are listed in the legend of Figure 2. b) Numbering of the protein sequences begins with the first ATG start codon (methionine). c) The E627K or D701N substitutions in the PB2 protein are critical for the adaptation of avian influenza A viruses to their mammalian hosts. Important residues discussed in the text are shaded gray. d) The Q235L mutation (Q226L in the H3 numbering system) increases the binding affinity of HA to the human receptor. e) The R294K mutation (R292K in the N2 numbering system) in the NA protein confers resistance to oseltamivir.

es have not been determined. This result may indicate the necessity for an extensive surveillance to investigate the accumulated effects of these virus substitutions on the pathogenesis of human.

The pathogenesis of the novel avian-origin H7N9 virus in humans remains unknown; however, a series of substitutions were found in Hangzhou H7N9 viruses which had been determined previously to be related with infection and severe diseases in animal models [12]. For example, the substitution at position 226 of the HA protein has been determined as pivotal residue in the binding of avian- or human-type receptor and, it has been suggested, that the presence of residue $226 \mathrm{~L}$ might increase the airborne transmission of the virus [4,13]. The Q226L substitution in the HA protein of $\mathrm{H} 5$ laboratory-mutated viruses was shown to cause the viruses to bind strongly to $\alpha-2,6$ human-like receptors $[5,14]$. However, we observed a Q226I substitution in the HA sequence from Hangzhou/1. Isoleucine and leucine are both hydrophobic residues which may imply that the Q226I mutation plays a similar major role in the $\alpha-2,6$ receptor binding and human adaptation of some of the new H7N9 viruses. Some of the sequences of the H3 subtype of human infected influenza viruses that we obtained from the Influenza Virus Resource database [9] also contained the Q226I mutation. However, this is the first report of the Q226I substitution at this site for the H7 subtype (Figure 4), which may indicate a novel host adaptation feature of the H7 virus [12]. The receptor binding properties of HAs that contain the Q226I substitution need direct experimental investigation.

Previous studies indicated that several substitutions in PB2 sequences were associated with efficient virus replication which contributed to the high pathogenicity of $\mathrm{H} 5 \mathrm{~N} 1$ viruses in mice [6-8]. Two amino acid positions in the PB2 
protein affect the growth of influenza viruses in mammalian cells [6-8]; namely, positions 627 (PB2-627) and 701 (PB2-701). In most human influenza viruses the residue at position 627 is lysine (PB2-627K) and in most avian viruses it is glutamic acid (PB2-627E). Thus, 627K in PB2 is a mammal-signature amino acid. The alignments of the publicly available H7N9 PB2 sequences revealed that the PB2 sequence from a human sample of the Zhejiang/DTIDJU01 virus had a 627E substitution (Figure 4). The Zhejiang/DTID-ZJU01 virus also had a special D701N mutation which was confirmed previously to be important for the high virulence of this virus in animal models $[8,15]$. Together, these data for the different important amino acid substitutions in the proteins of novel H7N9 viruses indicate a divergent adaptation mode for the influenza $\mathrm{A}$ virus in human $[16,17]$.

The genotypic diversities of the novel H7N9 viruses that we sequenced from the patients and the contact poultry market in Hangzhou, Zhejiang Province implied that these novel viruses exhibited rapid evolution. The results of this study may shed light on the understanding of the source and mode of transmission of these infections, and will provide a reference for the considerate selection of candidate vaccine strains.

This work was supported by the Hangzhou Key Medicine Discipline Fund for Public Health Laboratory sponsored by the Hangzhou government, National Basic Research Program of China (2010CB530303, 2011CB504703), and an intramural special grant for influenza virus research from Chinese Academy of Sciences (KSZD-EW-Z-002). We thank Dr. Gao George F. for his advice on the design of this study and for his critical review for the manuscript. We also thank the staff of the Microbiology Laboratory of Hangzhou Center for Disease Control and Prevention for their excellent technology support, and Dr. Zhu Dan for his interpretation of the patients' radiographs. The authors declare no financial or commercial conflict of interest.

1 Gao R, Cao B, Hu Y, et al. Human infection with a novel avian-origin influenza A (H7N9) virus. N Engl J Med, 2013, doi: 10.1056/NEJMoa1304459

2 Liu D, Shi W, Shi Y, et al. Origin and diversity of novel H7N9 avian influenza viruses causing human infection. Lancet, 2013, doi: 10.1016/S0140-6736(13)60938-1

3 Kageyama T, Fujisaki S, Takashita E, et al. Genetic analysis of novel avian A(H7N9) influenza viruses isolated from patients in China, February to April 2013. Eurosurveillance, 2013, 18: pii=20453

4 Herfst S, Schrauwen E J, Linster M, et al. Airborne transmission of influenza A/H5N1 virus between ferrets. Science, 2012, 336: 15341541

5 Imai M, Watanabe T, Hatta M, et al. Experimental adaptation of an influenza H5 HA confers respiratory droplet transmission to a reassortant H5 HA/H1N1 virus in ferrets. Nature, 2012, 486: 420428

6 Li Z, Chen H, Jiao P, et al. Molecular basis of replication of duck H5N1 influenza viruses in a mammalian mouse model. J Virol, 2005, 79: 12058-12064

7 Shinya K, Hamm S, Hatta M, et al. PB2 amino acid at position 627 affects replicative efficiency, but not cell tropism, of Hong Kong H5N1 influenza A viruses in mice. Virology, 2004, 320: 258-266

8 Steel J, Lowen A C, Mubareka S, et al. Transmission of influenza virus in a mammalian host is increased by PB2 amino acids $627 \mathrm{~K}$ or 627E/701N. PLoS Pathog, 2009, 5: e1000252

9 Bao Y, Bolotov P, Dernovoy D, et al. The influenza virus resource at the national center for biotechnology information. J Virol, 2008, 82: 596-601

10 Rodriguez F, Oliver J L, Marin A, et al. The general stochastic model of nucleotide substitution. J Theor Biol, 1990, 142: 485-501

11 Stamatakis A. RAxML-Vi-HPC: maximum likelihood-based phylogenetic analyses with thousands of taxa and mixed models. Bioinformatics, 2006, 22: 2688-2690

12 Jonges $\mathrm{M}$, Meijer A, Fouchier R A, et al. Guiding outbreak management by the use of influenza $\mathrm{A}(\mathrm{H} 7 \mathrm{Nx})$ virus sequence analysis. Eurosurveillance, 2013, 18: pii=20460

13 Russell C A, Fonville J M, Brown A E, et al. The potential for respiratory droplet-transmissible $\mathrm{A} / \mathrm{H} 5 \mathrm{~N} 1$ influenza virus to evolve in a mammalian host. Science, 2012, 336: 1541-1547

14 Fouchier R A, Garcia-Sastre A, Kawaoka Y, et al. Transmission studies resume for avian flu. Science, 2013, 339: 520-521

15 Chen Y, Liang W, Yang S, et al. Human infections with the emerging avian influenza A H7N9 virus from wet market poultry: clinical analysis and characterisation of viral genome. Lancet, 2013, doi: 10.1016/S0140-6736(13)60903-4

16 Quynh M L, Sakai-Tagawa Y, Ozawa M, et al. Selection of H5N1 influenza virus PB2 during replication in humans. J Virol, 2009, 83: 5278-5281

17 Li Q, Zhou L, Zhou M, et al. Preliminary report: epidemiology of the avian influenza A (H7N9) outbreak in China. N Engl J Med, 2013, doi: 10.1056/NEJMoa1304617

Open Access This article is distributed under the terms of the Creative Commons Attribution License which permits any use, distribution, and reproduction in any medium, provided the original author(s) and source are credited.

\section{Supporting Information}

Table S1 Clinical features of the patients on admission

Table S2 Molecular analysis of amino acid difference in the viral proteins between Hangzhou/1 isolate and other three reported H7N9 viruses

The supporting information is available online at life.scichina.com and www.springerlink.com. The supporting materials are published as submitted, without typesetting or editing. The responsibility for scientific accuracy and content remains entirely with the authors. 